\title{
Relevance of Somatostatin Receptors and Other Peptide Receptors in Pathology
}

\author{
Jean Claude Reubi, MD
}

\begin{abstract}
Receptors for regulatory peptides can be overexpressed by several diseases, in particular by neoplasms. This review summarizes the current status of knowledge in this field, on the basis of in vitro receptor studies and with emphasis on receptors for somatostatin as well as for substance P (SP), vasoactive intestinal polypeptide (VIP), and cholecystokinin. It evaluates the existing and potential clinical implications of the findings for diagnosis and therapy and discusses the role of the pathologist in this context.
\end{abstract}

Key Words: Regulatory peptide receptors; tumors; peritumoral vessels; somatostatin; receptor autoradiography.

Address correspondence to Dr. Jean Claude Reubi, Professor of Pathology, Division of Cell Biology and Experimental Cancer Research, Institute of Pathology, University of Berne, Murtenstrasse 31, CH-3010 BERNE (Switzerland).

Endocrine Pathology, vol. 8, no. 1, 11-20, Spring 1997 (C) Copyright 1997 by Humana Press Inc. All rights of any nature whatsoever reserved. 1046-3976/97/8:1 1-20/\$10.50

\section{Introduction}

During the last decades, endocrine pathology has been involved in understanding the origin, role, and diagnostic implications of the peptide hormones excessively synthesized and secreted by endocrine tumors. Recently, another basic aspect of endocrine function of these tumors has emerged: the high expression of membrane-bound receptors for several peptides. These receptors, potential new tumor markers, are of particular interest to pathologists because of both diagnostic and therapeutic implications.

Membrane receptors are key molecules for cellular interactions as they represent the specific molecular targets of a particular endogenous substance, which acts on a target tissue. An adequate receptor status is, therefore, important for the normal homeostasis of an organ, whereas quantitative or qualitative alterations of the receptors may indicate the presence of a disease, or even represent the biochemical basis of that disease. Specific drugs designed to have a high affinity for these receptors can be used therapeutically. Receptors can also be used for diagnostic purposes, as targets for specific radiolabeled ligands designed as high affinity synthetic analogs of the corresponding endogenous substances.

\section{Peptide Hormones and Their Receptors}

The regulatory peptides (Table 1 ) represent an interesting group of molecules known to act usually on multiple targets in the human body, at extremely low concentrations [1]. Targets of these peptides are primarily the brain and the gastrointestinal tract, but include also the endocrine system, the kidneys, the immune, vascular, and peripheral nervous systems. These regulatory peptides control and modulate the function of almost all key organs and metabolic processes. The peptide action is mediated through specific membranebound receptors, usually of the type of G-protein coupled, seven transmembrane domains containing proteins. Receptor subtypes with their own ligand specificity and second messenger systems have been discovered for almost all peptides. This fact 


\begin{tabular}{ll}
\hline Table 1. Major Regulatory Peptides & \\
\hline Opioid peptides & Bradykinin \\
Substance P & Bombesin/gastrin-releasing peptide \\
Gastrin & Neuropeptide Y \\
Cholecystokinin & Galanin \\
Vasoactive intestinal peptide & Atrial natriuretic factor \\
Pituitary adenylate cyclase activating & Neurotensin \\
$\quad$ peptide & \\
Alpha-melanocyte-stimulating hormone & Secretin \\
Arginine-vasopressin & Somatostatin \\
Oxytocin & TRH \\
Angiotensin & LHRH \\
Calcitonin & CRF \\
Endothelin & GHRH \\
\hline
\end{tabular}

results in an increased diversification of the mode of action of particular peptides.

For the pathologist and clinician alike, it is of interest to know which peptide receptor can be altered, in which type of pathology such alterations occur, and the practical consequences for their diagnostic work. Some of the salient findings in the peptide hormone receptor field, and the clinical consequences are summarized, with particular emphasis on somatostatin receptors.

\section{Somatostatin and Somatostatin Receptors}

Somatostatin exists as 14-amino acid (somatostatin-14) or 28-amino acid (somatostatin-28) long peptide, present mainly in the central nervous system, the hypothalamo-pituitary system, the gastrointestinal tract, the exocrine and endocrine pancreas, and the immune system. It exerts primarily an inhibitory effect on a wide spectrum of physiological functions, including inhibition of peptide hormone secretion [2]. Somatostatin can thus be considered as a neurotransmitter, a neurohormone, or a local hormone acting via autocrine or paracrine mechanisms. Moreover, somatostatin appears to play a role in cancer: In many animal tumor models and cultured tumor cell lines, somatostatin and somatostatin analogs inhibit tumor growth. Further, octreotide, the first clinically used stable somatostatin analog, successfully controls hormonal hypersecretion in patients with pituitary tumors, carcinoids, and islet cell tumors, and may occasionally inhibit tumor growth as well.

These somatostatin and octreotide actions are mediated by specific, high affinity somatostatin receptors located on the plasma membrane of the target cells. Indeed, the presence of somatostatin receptors has been demonstrated in various regions of the normal brain; the leptomeninx; the anterior pituitary; the endocrine and exocrine pancreas; the mucosa of the gastrointestinal tract; the normal human kidney and the prostate; parts of the peripheral nervous system (gastrointestinal plexus); and cells of the immune and vascular systems [1]. To date five human somatostatin receptor subtypes $\mathrm{sst}_{1}, s_{2} \mathrm{t}_{2}$, $s s t_{3}, s s t_{4}$, and $s s t_{5}$ have been cloned and partially characterized. They have distinct, often overlapping patterns of expression. The subtypes belong to a superfamily of G-protein coupled receptors that can functionally couple to the inhibition of adenylyl cyclase. Pharmacological studies showed that all five human subtypes bind somatostatin-14 and somatostatin-28 with high affinity. However, there are differences in the binding affinities of the structural analogs of somatostatin: For instance, octreotide binds with a high affinity to the sst $_{2}$ and sst $_{5}$ human receptor subtypes and with a moderate affinity to $s_{3}$, but not to

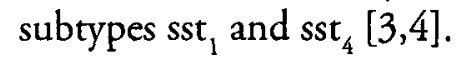

\section{In Vitro Detection of Somatostatin Receptors in Human Tumors}

Within the last decade, it has been shown, surprisingly, that a wide variety of endocrine as well as "nonendocrine" human 


\begin{tabular}{ll}
\hline Table 2. Incidence of Human Tumors that Express Somatostatin Receptors \\
\hline $\begin{array}{l}\text { Neuroendocrine tumors (pituitary adenomas, ICC, } \\
\text { carcinoids, paragangliomas, MTC, } \\
\text { pheochromocytomas, SCLC) }\end{array}$ & High \\
$\begin{array}{l}\text { Tumors of the nervous system (astrocytomas, } \\
\quad \text { neuroblastomas, medulloblastomas, } \\
\quad \text { meningiomas) }\end{array}$ & High \\
$\begin{array}{l}\text { Renal cell carcinomas } \\
\text { Malignant lymphomas }\end{array}$ & High \\
$\begin{array}{l}\text { Prostate cancers }{ }^{a} \\
\text { Breast cancers }\end{array}$ & High \\
$\begin{array}{l}\text { Ovarian, pancreatic, }{ }^{b} \text { and colonic cancers } \\
\text { NSCLC, glioblastomas, schwannomas }\end{array}$ & High \\
${ }^{a}$ No sst $_{2}$ (octreotide-preferring somatostatin receptors) but at least sst, is present [9]. \\
${ }^{b}$ No sst $_{2}$, but sst $_{1}$ and sst ${ }_{4}$ may be present [10]. & Low \\
\hline
\end{tabular}

tumors express somatostatin receptors (Table 2), as measured in vitro with radioligand binding techniques using ${ }^{125}$ I-labeled somatostatin analogs, either in tumor homogenates or on tumor sections (receptor autoradiography) [5].

The highest incidence of somatostatin receptors are observed in neuroendocrine tumors. Most GH- and TSH-producing pituitary adenomas and several nonsecreting adenomas contain somatostatin receptors, as do many endocrine gastroenteropancreatic tumors, pheochromocytomas, paragangliomas, medullary thyroid carcinomas, and small cell lung cancers (Table 2). Most of the aforementioned tumors belong to the group of apudomas (i.e., tumors thought to arise from the amine precursor uptake and decarboxylation cell). These tumors have generally a high density of somatostatin receptors, although a great individual variability is usually observed (e.g., more than a 10-fold difference in somatostatin receptor density within a particular tumor type). Therefore, it has been suggested that somatostatin receptors, especially of the octreotide-preferring $s t_{2}$ subtype, are valuable markers for the diagnosis of neuroendocrine tumors. For instance, the octreotide receptor status clearly differentiates between endocrine and exocrine pancreatic carcinomas, the latter being always receptor-negative. However, also those neuroendocrine tumors that remain poorly differentiated (i.e., atypical carcinoids) appear to lack these receptors. Thus, it is presently believed that primarily the well-differentiated neuroendocrine tumors express somatostatin receptors (Fig. 1).

A second group of human tumors, originating in the nervous system, frequently expresses somatostatin receptors (Table 2) [5], which is more than $80 \%$ of astrocytomas, a high percentage of neuroblastomas, and all meningiomas.

Third, malignant lymphomas, clearly not neuroendocrine tumors, have been recently identified as having a high incidence of somatostatin receptors. Thus, somatostatin receptors cannot be considered exclusively as a neuroendocrine marker. More than $70 \%$ of renal cell carcinomas, and approx $50 \%$ of breast tumors have also been shown to possess somatostatin receptors, including those breast tumors with neuroendocrine characteristics. Conversely, colorectal and ovarian tumors are characterized by a much lower incidence of somatostatin receptors. A large group of human neoplasms, including glioblastomas, nonsmall cell lung cancers, and many squamous cell carcinomas, do not express significant amounts of somatostatin receptors. Thus, somatostatin receptors are not "universal" markers for human neoplasms.

Human tumors can also express different somatostatin receptor subtypes, as their normal tissue counterparts do [5,6]. Pituitary adenomas appear to express all five sst subtypes, with particularly high levels of sst $_{2}$ and sst $_{5}$ [7], as shown with reverse transcriptase PCR and ribonuclease protection assay. Also, in situ hybridization for sst subtype mRNAs showed that various human tumor types can express one or several of the somatostatin receptor subtypes. 

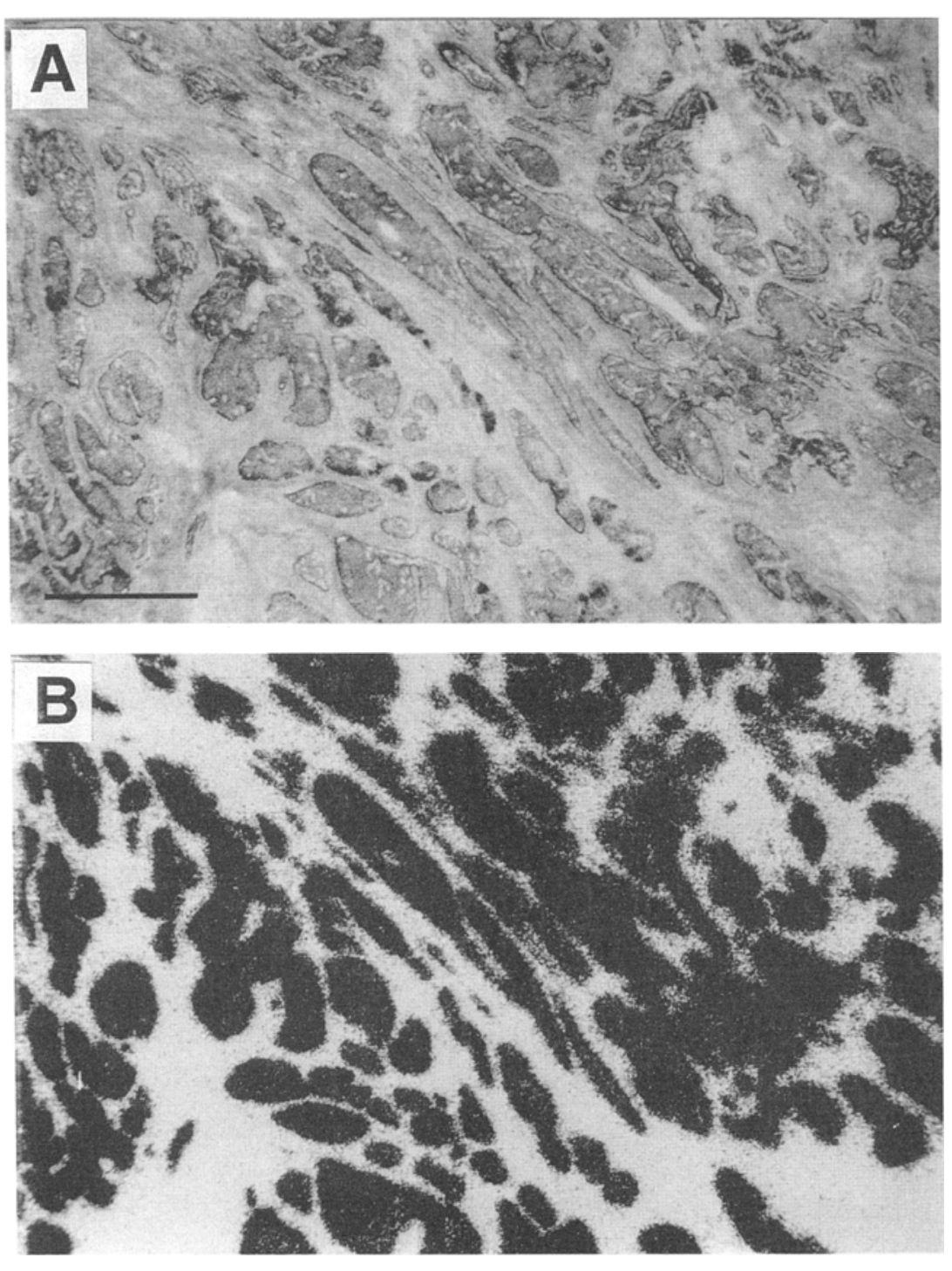

Fig. 1. Somatostatin receptors in an intestinal carcinoid tumor. (A) H\&E stained section. Bar $=1 \mathrm{~mm}$. (B) Autoradiogram showing total binding of ${ }^{1251}$ - [Tyr $\left.{ }^{3}\right]-$ octreotide. The tumor has a high density of somatostatin receptors (black areas). Nonspecific binding is negligible.

The most frequently expressed subtype appears to be sst ${ }_{2}$. This fact is biologically important, since sst $_{2}$ may act, under certain circumstances, similar to a tumor suppressor gene: Expression of sst ${ }_{2}$ in BxPC3 cells was indeed shown to massively inhibit their growth [8]. This high incidence of sst ${ }_{2}$ is also extremely important for somatostatin receptor imaging and therapy of tumors with octreotide-like ligands because the $s{ }_{2}$ receptor has the highest affinity for octreotide among all somatostatin receptor subtypes. Conversely, it should be emphasized that there are several tumors that do not express octreotide-preferring somatostatin receptors (sst $)_{2}$, such as prostate, pancreatic, and probably ovarian adenocarcinomas, as well as some insulinomas and medullary thyroid carcinomas $[5,9,10]$. These tumors will not be visualized by ${ }^{111}$ In-[DTPA, DPhe ${ }^{1}$-octreotide imaging nor will they respond to octreoride therapy. A different type of ligand with high affinity for all subtypes, that is, structurally more closely related to somatostatin- 14 or somatostatin-28 than to octreotide, would be required to overcome these difficulties.

\section{Somatostatin Receptors in Nonneoplastic Tissues}

Somatostatin receptors have been shown to mediate somatostatin actions in the immune, vascular, and nervous systems. Thus, it was not too müch of a surprise to observe that nonneoplastic alterations of these systems may be associated with changes in the density of these receptors. One example is the florid granuloma in sarcoidosis or tuberculosis that expresses somatostatin receptors on epithelioid cells [11]; sclerosing/regressing granulomasspontaneously or in response to treatment-do not express somatostatin receptors any more. Also, affected joints in active rheumatoid arthritis express a high density of somatostatin receptors, preferentially located in synovial vessels (Fig. 2). Further, in inflammatory bowel disease, somatostatin receptors are primarily overexpressed in the vascular system [12]. Finally, veins located in areas surrounding different types of tumors can overexpress somatostatin receptors [13]. This could be the molecular basis of an indirect effect of 


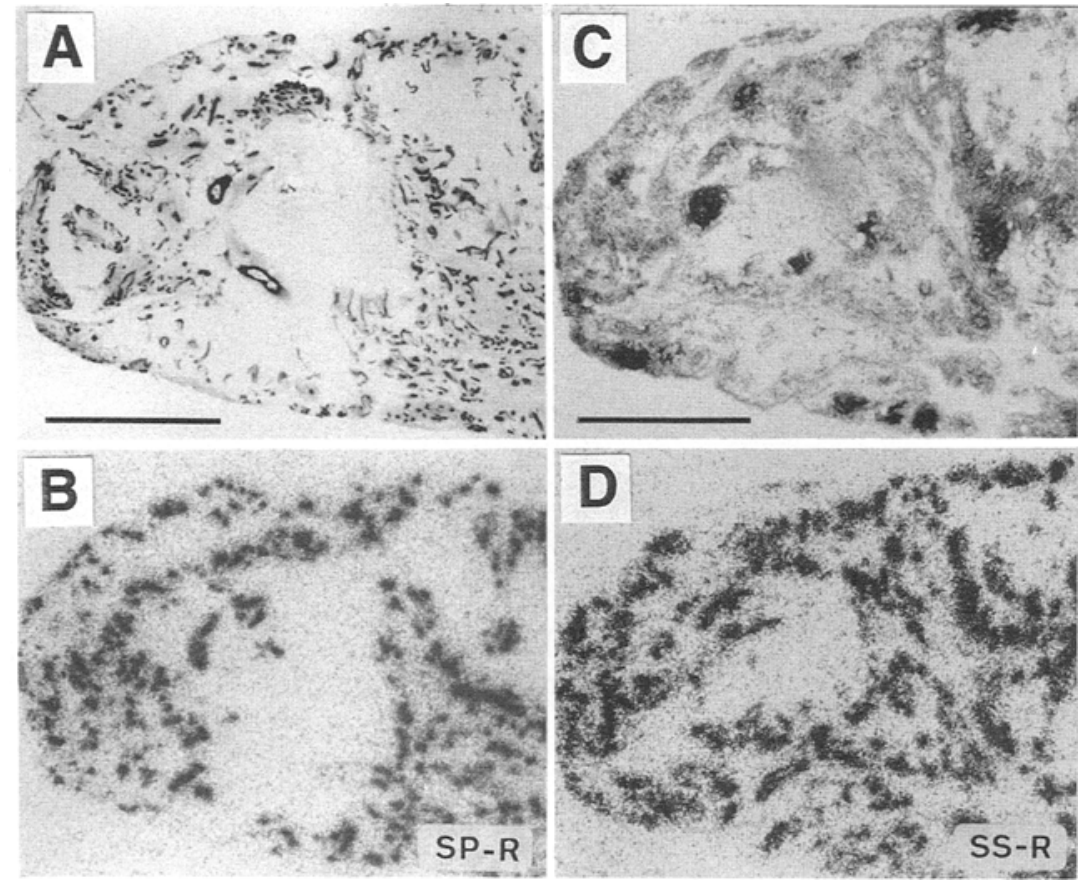

Fig. 2. Somatostatin and substance $P$ receptors in adjacent sections of synovial tissue from a rheumatoid arthritis patient. (A) Immunohistochemical demonstration of numerous vessels (FVIII-related antigen). Bar $=1 \mathrm{~mm}$. (B) Autoradiogram showing total binding of ${ }^{125} \mathrm{I}-$ Bolton-Hunter substance $P$. Nonspecific binding is negligible. Vessels are strongly substance $P$ receptor-positive. (C) H\&E stained, adjacent section to $A$ Bar $=1 \mathrm{~mm}$. (D) Autoradiogram showing total binding of ${ }^{125}$-[Tyr $\left.{ }^{3}\right]$-octreotide. Nonspecific binding is negligible. The veins are somatostatin receptor-positive. patient and subsequent whole-body gamma camera scanning, has been developed and is now widely used as an efficient method for the localization of somatostatin receptor-positive tumors and their metastases, in particular GEP tumors [14].

3. In pituitary and GEP tumors, the somatostatin receptors are functional. Thus, the presence and density of somatostatin receptors correlate with the degree of inhibition of excessive hormone release by octreotide. The tumoral somatostatin receptor status can clearly be considered to be a predictive factor for the therapeutic efficacy of octreotide [15].

4. In neuroblastomas, and possibly in a subgroup of breast tumors, the somatostatin receptor status may have a prognostic value. Moertel et al. have shown indeed, an inverse relationship between the presence of somatostatin receptors and $\mathrm{N}$-myc oncogene expression in neuroblastomas [16]; in addition, the presence of somatostatin receptors in more than $60 \%$ of neuroblastomas clearly correlates with a favorable prognosis [16], a characteristic also observed by others [17].

5. Recent preliminary studies suggest that tumors with a high receptor density (i.e., GEP tumors) can be successfully treated with radiotherapy using radiolabeled somatostatin analogs [18].

\section{Role of the Pathologist}

What are the most important diagnostic, therapeutic, and prognostic implications of the aforementioned results?

1. The somatostatin receptor is a marker for differentiated neuroendocrine tumors, in vitro or in vivo.

2. In vivo somatostatin receptor scintigraphy, based on the iv injection of an ${ }^{111}$ In-labeled somatostatin analog to the
What is the role of the pathologist in these issues? By evaluating in vitro somatostatin receptors in tissue sections from surgical biopsies, the pathologist may play a decisive role in tumor typing and in the search of diagnostic, prognostic, or predictive clues such as increased densities of somatostatin receptors. In addition, the correlation of structural changes-for 
instance inflammation - and functional parameters may offer unique insights in basic mechanisms of disease. However, the somatostatin receptor measurement in diagnostic pathology has not yet been developed as a standard method.

There are two probable reasons for that. The first is related to the cumbersome method itself (i.e., in vitro receptor autoradiography on tissue sections) [1]. This is a powerful and very specific method to analyze the binding of 125 -iodine labeled radioligands to their receptors in 10-20 $\mu$ thick tissue sections, but the technique is time-consuming and requires specific laboratory facilities, expertise, and personnel acquainted with radioisotopic studies [1]. Rather than investing in these techniques, many surgical pathologists may prefer to wait for the development of adequate somatostatin receptor antibodies to perform immunohistochemistry in formalinfixed sections. The second reason is related to the impressively rapid development of in vivo somatostatin receptor scintigraphy. In most cases, it is tempting for the clinician to take advantage of this relatively simple in vivo technique rather than to request an in vitro somatostatin receptor evaluation. The in vivo scintigraphy gives obviously more clinical (or clinically usable) information than in vitro measurements. Not only does it measure the somatostatin receptor status of diseased tissues, but also their localization in the patient. The development of a FDA-approved kit (Octreoscan ${ }^{\circledR}$ ) has contributed to the worldwide use of this in vivo method. The in vitro receptor autoradiography methods, conversely, have a more experimental character, but allow the histological localization of somatostatin receptors (e.g., in blood vessels) and thus provide a unique basis for the correct histopathologic interpretation of scintigraphic observations made in vivo.

\section{Evaluation of Other Peptide Receptors in Diseases}

Somatostatin receptors are not expressed in all neoplasms. Some of the most devastating tumors do not express significant amounts of somatostatin receptors. Therefore, it is mandatory to search in vitro for overexpression of other regulatory peptide receptors [1]. The first promising findings are emerging and are summarized in the following paragraphs.

Thus, in a recent study, we identified a high prevalence of vasoactive intestinal polypeptide (VIP) receptors in almost all human epithelial tumors [19], including somatostatin receptor-negative tumors. These observations are in keeping with the recent report on localization of tumors by VIP receptor scintigraphy in patients [20].

We have also found that receptors for the peptide substance $P(S P)$ are expressed in many neoplasms, such as in glial tumors, medullary thyroid carcinomas, and breast tumors, but rarely in gastrointestinal tumors or lymphomas [21]. Interestingly, all tumors, including the receptor-negative ones, displayed many SP receptors in tumoral and peritumoral vessels [21]. An overexpression of SP-R in vessels had been reported earlier by Mantyh et al. [22] in inflammatory bowel diseases and by Walsh et al. [23] in rheumatoid arthritis. Therefore, a dual approach with SP analogs, that is, based on the tumoral and vascular receptor expression, may be considered [21] for the diagnosis or treatment of these diseases.

Finally, there is recent evidence of an overexpression of CCK-B/gastrin receptors in most MTC and in SCLC $[24,25]$. Conversely, neither differentiated thyroid cancers nor nSCLC express CCK-B/gastrin receptors. Therefore, CCK-B/gastrin receptors could play an important role for the "in vivo typing" of thyroid and lung tumors, before histopathological evaluation. 


\section{SS VIP SP CCK-B CCK-A}

MTC

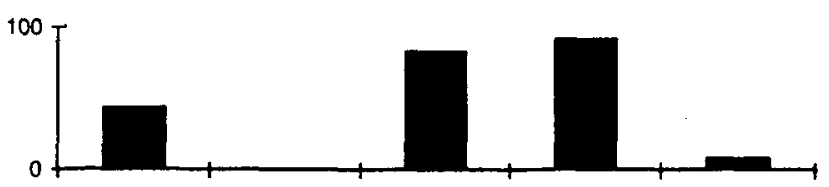

nSCLC

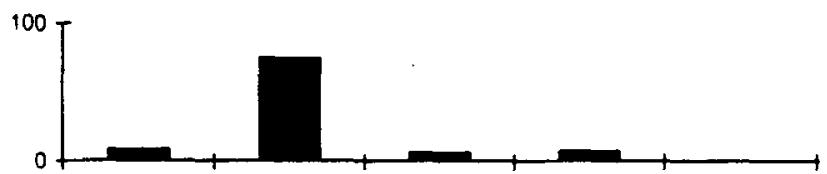

Fig. 3. Incidence of various peptide receptors in selected human tumor types. The incidence (in \%) of the tumors expressing the various receptors is given for two types of tumors. The results are adapted from $[19,21,24,29]$. SS-R, VIP-R, SP-R, and CCK-R data are from different patient groups, and thus represent a statistical rather than individual positivity for the tumors. Flat histogram means absence of the respective receptor in the corresponding tumor.

Gastrin strongly stimulates cell proliferation. Thus, gastrin receptors may be involved in the pathogenesis of these tumors, and CCK-B/gastrin receptor antagonists might be of therapeutic value $[24,25]$.

Thus, multiple peptide receptors can be expressed by individual human tumors. Preliminary results, seen in Fig. 3, which compare the incidence rate of several peptide receptors in selected tumors, seem to indicate that a highly variable, but perhaps tumor type-specific receptor pattern, exist among these tumors. Medullary thyroid carcinomas, for example, may express receptors for substance $P$, somatostatin, and gastrin (Figs. 3 and 4), but lack VIP receptors. Conversely, nonsmall cell lung carcinomas may often express VIP receptors, but rarely receptors for substance $\mathrm{P}$, somatostatin, or gastrin (Fig. 3). Since the number of existing regulatory peptides is large, it is likely that several other peptide receptors may be identified in the near future in high incidence and high density in specific diseases. This may allow to perform in vitro
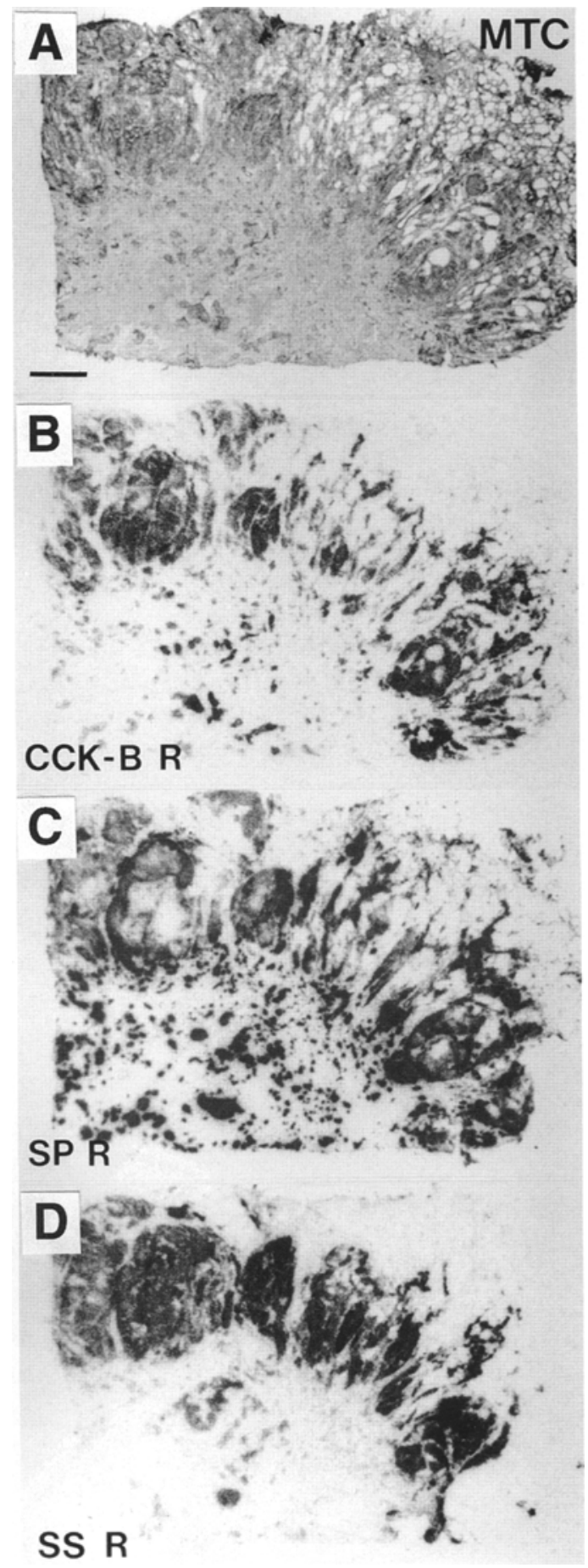

Fig. 4. Multiple peptide receptors expressed by a medullary thyroid carcinoma. (A) H\&E stained section. Bar $=1 \mathrm{~mm}$. (B) Autoradiogram showing total binding of ${ }^{125}$-gastrin. (C) Autoradiogram showing total binding of ${ }^{125}$-substance P. (D) Autoradiogram showing total binding of ${ }^{125}$ - $\left[\mathrm{Tyr}^{3}\right]$-octreotide. The tumor expresses CCK-B/gastrin-, substance $P$-, and somatostatin-receptors concomitantly. 


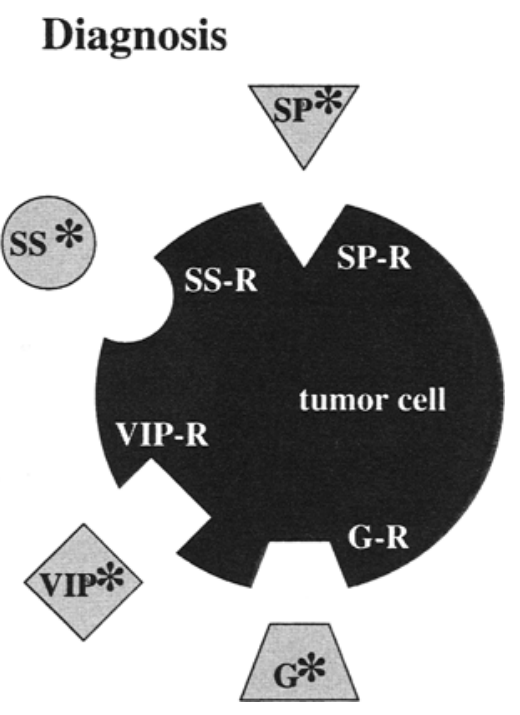

Therapy: growth inhibition

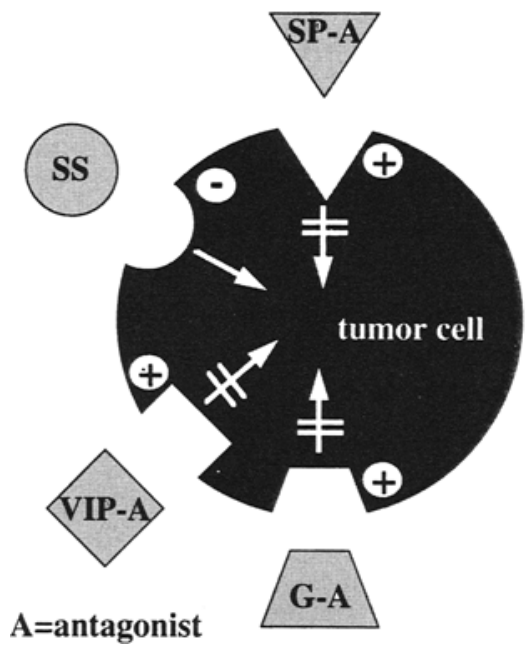

Fig. 5. Diagnostic and therapeutic applications of the multiple peptide receptors expressed by individual tumors. (A) Tumor diagnosis using a cocktail of radiolabeled $\left(^{*}\right)$ peptides (specific binding) for in vivo signal amplification in the tumor. (B) Tumor growth inhibition based on the concomitant therapeutic use of multiple peptide analogs, either agonists of growth-inhibiting peptides (SS) or antagonists (= A) of growth-stimulating peptides (VIP, SP, gastrin).

or in vivo tumor "typing" by determining a "profile" characterized by different expressions of several peptide receptors. This identification of tumor-or disease-specific receptor phenotypes could thus provide specific targets for diagnostic in vivo imaging and, possibly, for therapy [1].

Of course, peptides are not the only regulators of a cell; growth factors, cytokines, and other molecules also play a major regulatory role and are able to "cross-talk" with peptides to modulate cell responses. Growth factor and cytokine receptors are also altered in neoplastic and nonneoplastic diseases [26-28]. These alterations will affect the interaction of growth factors and cytokines with peptides, and influence diagnostic and therapeutic strategies.

\section{Future Developments}

A promising strategy will be to evaluate and take advantage of the simultaneous expression of several peptide receptors in a given tumor type. This receptor phenotyping of individual tumors may lead to novel diagnostic and therapeutic possibilities: First, the use of an intravenous injection of a cocktail of peptide radioligands that bind specifically to a given tumor may massively increase the signal given by tumors scanned in vivo (Fig. 5A); second, the simultaneous therapeutic use of several peptide analogs acting synergistically against tumor proliferation could considerably improve the efficacy of peptide therapy (Fig. 5B). Since it can be foreseen that such a "receptor phenotyping" of individual tumors will be difficult and costly to perform in vivo, it is likely that this evaluation, which can be done with in vitro receptor autoradiography on small biopsies, will be added to the armamentarium of the diagnostic pathologist, especially if rapid and reliable techniques to reveal receptors for peptides (i.e., using adequate antibodies against the various peptide receptors) become available.

\section{References}

1. Reubi JC. Neuropeptide receptors in health and disease: the molecular basis for in vivo imaging. J Nucl Med 36:1825$1835,1995$.

2. Lamberts SWJ, Krenning EP, Reubi JC. The role of somatostatin and its analogs in the diagnosis and treatment of tumors. Endocr Rev 12:450-482, 1991.

3. Hoyer D, Bell GI, Berelowitz M, Epelbaum J, Feniuk W, Humphrey PPA, O'Carroll A, Patel YC, Schönbrunn A, Taylor JE, Reisine T. Classification and nomenclature of somatostatin receptors. Trends in Pharmacol Sci 16:86-88, 1995.

4. Reisine T, Bell GI. Molecular biology of somatostatin receptors. Endocr Rev 16:427442, 1995.

5. Reubi JC, Krenning E, Lamberts SWJ, Kvols L. In vitro detection of somatostatin receptors in human tumors. Metabolism 41:104110, 1992. 
6. Reubi JC, Schaer JC, Waser B, Mengod G. Expression and localization of somatostatin receptor SSTR1, SSTR2 and SSTR $3 \mathrm{mRNAs}$ in primary human tumors using in situ hybridization. Cancer Res 54:3455-3459, 1994.

7. Greenman Y, Melmed S. Expression of three somatostatin receptor subtypes in pituitary adenomas: evidence for preferential SSTR5 expression in the mammosomatotroph lineage. J Clin Endocrinol Metab 79:724729, 1994.

8. Rauly I, Saint-Laurent N, Delesque N, Buscail L, Esteve J, Vaysse N, Susini C. Induction of a negative autocrine loop by expression of sst2 somatostatin receptor in NIH $3 \mathrm{~T} 3$ cells. J Clin Invest 97:1874-1883, 1996.

9. Reubi JC, Waser B, Schaer JC, Markwalder R. Somatostatin receptors in human prostate and prostate cancer. J Clin Endocrinol Metab 80:2806-2814, 1995.

10. Buscail L, Saint-Laurent N, Chastre E, Vaillant J, Gespach C, Capella G, Kalthoff H, Lluis F, Vaysse N, Susini C. Loss of sst2 somatostatin receptor gene expression in human pancreatic and colorectal cancer. Cancer Res 56:1823-1827, 1996.

11. van Hagen PM, Krenning EP, Reubi JC, Kwekkeboom D, Oei HY, Mulder AH, Laissue J, Hoogstede HC, Lamberts SWJ. Somatostatin analogue scintigraphy in granulomatous diseases. Eur J Nucl Med $21: 497-$ 502,1994.

12. Reubi JC, Mazzucchelli L, Laissue J. Intestinal vessels express a high density of somatostatin receptors in human inflammatory bowel disease. Gastroenterology 106:951$959,1994$.

13. Reubi JC, Laissue JA. Multiple pathways of somatostatin action in neoplastic disease. Trends Pharmacol Sci 16:110-115, 1995.

14. Krenning EP, Kwekkeboom DJ, Pauwels S, Kvols LK, Reubi JC. Somatostatin receptor scintigraphy. In: Freeman LM, ed. Nuclear Medicine Annual. New York: Raven Press, 1995; 1-50.

15. Kvols LK, Reubi JC, Horisberger U, Moertel CG, Rubin J, Charboneau JW. The presence of somatostatin receptors in malignant neuroendocrine tumor tissue predicts responsiveness to octreotide. Yale J Biol Med 65:505$518,1992$.
16. Moertel CL, Reubi JC, Scheithauer BS, Schaid DJ, Kvols LK. Expression of somatostatin receptors in childhood neuroblastoma. Am J Clin Pathol 102:752-756,1994.

17. O'Dorisio MS, Chen F, O'Dorisio M, Wray D, Qualman SJ. Characterization of somatostatin receptors on human neuroblastoma tumors. Cell Growth Differ 5:1-8, 1994.

18. Krenning EP, Valkema R, Kooij PPM, Breeman WAP, Bakker WH, de Herder WW, van Eijck CHJ, Kwekkeboom DJ, Postema PTE, Kvols LK, Reubi JC, Pauwels S. Radionuclide therapy with (111-In-DTPA-DPhe-1)-octreotide. Preliminary data of a phase 1 study. In: Continuing Education Course Manual. Reston, VA: Society of Nuclear Medicine, 1996; 148-156.

19. Reubi JC. In vitro identification of vasoactive intestinal peptide receptors in human tumors: implications for tumor imaging. J Nucl Med 36:1846-1853, 1995.

20. Virgolini I, Raderer M, Kurtaran A, Angelberger P, Banyai S, Yang Q, Li S, Banyai M, Pidlich J, Niederle B, Scheithauer W, Valent P. Vasoactive intestinal peptide-receptor imaging for the localization of intestinal adenocarcinomas and endocrine tumors. $N$ Engl J Med 331:1116-1121, 1994.

21. Hennig IM, Laissue JA, Horisberger U, Reubi JC. Substance $P$ receptors in human primary neoplasms: tumoural and vascular localisation. Int J Cancer 61:786-792, 1995.

22. Mantyh CR, Gates TS, Zimmerman RP, Welton ML, Passaro EP, Vigna SR, Maggio JE, Kruger L, Mantyh PW. Receptor binding sites for substance $P$, but not substance $K$ or neuromedin $\mathrm{K}$, are expressed in high concentrations by arterioles, venules, and lymph nodules in surgical specimens obtained from patients with ulcerative colitis and Crohn disease. Proc Natl Acad Sci USA 85:32353239, 1988.

23. Walsh DA, Mapp PI, Wharton J, Rutherdorf RAD, Kidd BL, Revell PA, Blake DR, Polak JM. Localisation and characterisation of substance $\mathrm{P}$ binding to human synovial tissue in rheumatoid arthritis. Ann Rheum Dis 51:313-317, 1992.

24. Reubi JC, Waser B. Unexpected high incidence of cholecystokinin $B /$ gastrin receptors in human medullary thyroid carcinomas. Int J Cancer 67:644-647, 1996. 
25. Matsumori $Y$, Katakami N, Ito $M$, Taniguchi T, Iwata N, Takaishi T, Chihara K, Matsui T. Cholecystokinin-B/gastrin receptor. A novel molecular probe for human small cell lung cancer. Cancer Res 55:276-279,1995.

26. Reubi JC, Horisberger U, Lang W, Koper JW, Braakman R, Lamberts SWJ. Coincidence of EGF receptors and somatostatin receptors in meningiomas but inverse, differentiationdependent relationship in glial tumors. Am J Pathol 134:337-344, 1989.

27. Moody TW. Peptides and growth factors in non-small cell lung cancer. Peptides 17:545555, 1996.

28. Zola H. Analysis of receptors for cytokines and growth factors in human disease. Disease Markers 12:225-240, 1996.

29. Reubi JC. High incidence of CCK-B/gastrin receptors in human medullary thyroid cancers and small cell lung cancers: differential diagnostic implications. J Nucl Med 37:348P, 1996. 